\title{
Lipoprotein(a) Levels in Thyroid Disorders
}

\author{
Pop-Radu Cristina Corina ${ }^{1}$, Gliga Mirela² \\ 1 Department of Endocrinology, Faculty of Medicine, University of Medicine and Pharmacy, Tîrgu Mureș, Romania \\ 2 Department of Internal Medicine, Faculty of Medicine, University of Medicine and Pharmacy, Tîrgu Mureș, Romania
}

\begin{abstract}
Objective: The aim of this study was to assess the serum levels of Lipoprotein(a) [Lp(a)] in subjects with thyroid disorders, as well as to investigate their relationship with lipid profile and the markers of thyroid function and autoimmunity, admitting that elevated Lp(a) levels and dyslipidemia caused by thyroid disorders synergistically increased the atherogenic process.

Methods: This study enrolled 38 subjects with hypothyroidism, 30 with hyperthyroidism and 55 with euthyroidism. The following parameters were measured: Lp(a), apolipoprotein Al (apo Al), apolipoprotein B (apo B), total cholesterol (TC), triglyceride (TG), low-density lipoprotein $(\mathrm{LDL})$, high-density lipoprotein (HDL), very-low-density lipoprotein (VLDL), thyroid stimulating hormone (TSH), free thyroxine (FT4), triiodothyronine (T3), thyroid-peroxidase antibody (TPO-Ab).

Results: $L p(a)$ was found with increased mean serum levels in hypothyroid subjects $(483.28 \pm 281.55 \mathrm{mg} / \mathrm{L})$. Hyperthyroid subjects showed normal levels $(253.13 \pm 94.29 \mathrm{mg} / \mathrm{L})$ of $\mathrm{Lp}(\mathrm{a})$, but significantly lower than those with hypothyroidism and slightly increased levels in the euthyroid subjects (305 $\pm 100.44 \mathrm{mg} / \mathrm{L})$. In hypothyroidism a significant positive correlation between Lp(a) and TSH, apo B, TC, TG, TC/HDL, VLDL levels and a negative correlation with FT4, T3 and apo Al/B $(p<0.05)$ was observed. No correlations were found between serum Lp(a) levels, lipids profile and thyroid function parameters in hyperthyroid subjects, neither with TPO-Ab.

Conclusions: The association of hypothyroidism with increased levels of $L p(a)$ seems to increase the already high cardiovascular risk in the hypothyroid subjects, while increased levels of $L p(a)$ represents independently a relevant cardiovascular risk factor.
\end{abstract}

Keywords: hypothyroidism, hyperthyroidism, Lipoprotein(a)

Received: 13 May 2012

\section{Introduction}

Lipoprotein(a) $[\mathrm{Lp}(\mathrm{a})]$ was found in human plasma by Berg in 1963 as a genetic variant of low-density lipoprotein (LDL) [1], subsequently proving to be a significant independent risk factor for cardiovascular disease (CVD) $[2,3,4]$. The power of this correlation appears to be similar to that of systolic blood pressure and serum triglycerides (TG), but less significant than LDL, total cholesterol (TC) and apolipoprotein AI (apo AI) [2]. $\mathrm{Lp}(\mathrm{a})$ is a particle in which apolipoprotein B-100 (apo B100) is linked by a single interchain disulfide bridge to a unique glycoprotein apoLipoprotein(a) [apo(a)] [3]. Apo(a) is homologous to plasminogen, and its similarity to plasminogen indicates a prothrombogenic role for $\mathrm{Lp}(\mathrm{a})$, whereas the similarity of Lp(a) to LDL suggests a proatherogenic role $[4,5]$. It has been shown that high plasma $L p(a)$ levels are closely associated with arterial thrombosis, such as myocardial infarction and cerebral infarction [2-8]. Thyroid disorders are associated with lipid alterations, through different mechanisms, in almost all stages of lipid metabolism, mainly concerning TC and LDL and not so often for high-density lipoprotein (HDL), TG, Lp(a), apo A1, and apo B. Qualitative alterations of lipids have been also reported, including atherogenic and oxidized LDL and HDL particles [8]. In thyroid disorders dyslipidemia coexists with various metabolic abnormalities and induces insulin resistance and oxidative

Correspondence to: Cristina Corina Pop-Radu

E-mail: ccorinaradu@yahoo.com stress via a vicious cycle [9]. In association, hemodynamic alterations induced by thyroid hormones might explain the increased risk of coronary artery disease, cerebral ischemia, and angina pectoris in elderly, and possibly ischemic stroke in younger patients with overt or subclinical hyperthyroidism [10]. Even within the normal range of thyroid-stimulating hormone (TSH) values, a linear increase of TC, LDL and TG and a linear decrease in HDL levels has been noticed, all these being correlated with the increasing levels of TSH [11]. There is a general interest whether $\mathrm{Lp}(\mathrm{a})$ is under hormonal control. The role of thyroid hormones in the plasma concentration of $\operatorname{Lp}(\mathrm{a})$ has not been fully clarified, the results of different studies being contradictory.

The aim of this study was to assess the serum levels of $\mathrm{Lp}(\mathrm{a})$ in subjects with thyroid disorders, as well as to investigate their relationship with lipid profile and the markers of thyroid function and autoimmunity, admitting that elevated Lp(a) levels and dyslipidemia caused by thyroid disorders synergistically increased the atherogenic process.

\section{Methods}

The investigated parameters were: $\mathrm{Lp}(\mathrm{a})$, apo AI, apo B, TC, TG, LDL, HDL, very-low-density lipoprotein (VLDL), $\mathrm{TSH}$, free thyroxine (FT4), triiodothyronine (T3) and thyroid-peroxidase antibody (TPO-Ab) after a written informed consent. Apo AI/B, TC/HDL and LDL/HDL ratios were calculated. We analyzed the correlations between serum levels of $\operatorname{Lp}(\mathrm{a})$ and investigated parameters in subjects with hypothyroidism, hyperthyroidism and euthyroidism. 
Table I. Clinical variables and $L p(a)$ levels of the study groups

\begin{tabular}{lccc}
\hline Patients & Euthyroid & Hypothyroid & Hyperthyroid \\
\hline No. & 55 & 38 & 30 \\
BMl $\left(\mathrm{kg} / \mathrm{m}^{2}\right)$ & $23.82 \pm 4.51$ & $24.62 \pm 2.42$ & $22.18 \pm 3.19$ \\
Mean age & $38.30 \pm 13.52$ & $48.6 \pm 13.25$ & $41.53 \pm 12.29$ \\
Gender & $44 \mathrm{~F}: 11 \mathrm{M}$ & $23 \mathrm{~F}: 15 \mathrm{M}$ & $25 \mathrm{~F}: 5 \mathrm{M}$ \\
\hline \multicolumn{4}{c}{$\mathrm{Lp}(\mathrm{a}) \mathrm{mg} / \mathrm{dL}$} \\
\hline Mean \pm SD & $305 \pm 100.44$ & $483 \pm 281.55$ & $253 \pm 94.3$ \\
Range & $150-830$ & $214-1550$ & $140-530$ \\
\hline
\end{tabular}

$\mathrm{BMI}$ - body mass index, $\mathrm{F}$ - females, $\mathrm{M}$ - males

The study groups included 38 subjects with overt hypothyroidism, 30 with hyperthyroidism and 55 with euthyroidism. The study was randomized, descriptive casecontrol type.

The hypothyroid group included subjects with overt hypothyroidism, where other causes of secondary dyslipidemia were excluded and who have not received hormone replacement therapy within 6 months prior to their inclusion in the study. In the hyperthyroid group we enrolled subjects with different clinical forms of hyperthyroidism who did not follow any specific antithyroid treatment until inclusion in the study. In the control group we included euthyroid patients without any secondary cause of dyslipidemia.

Subjects with severe obesity, diabetes, nephrotic syndrome, renal failure, liver disease, those who were receiving thiazides, chlorthalidone, beta-blockers, anabolic steroids, glucocorticoids, estrogen, progesterone, androgens, oral contraceptives, tamoxifen, raloxifene, retinoids (isotretinoin), cyclosporine, phenobarbital, phenytoin, carbamazepine were not included in the study.

$\mathrm{Lp}$ (a) was determined by an immunoturbidimetric method, using a specific antiserum-immunoprecipitation in liquid phase. Quantitative measurements were made using a photometer at a wavelength of $340 \mathrm{~nm}$. Values for individual samples were compared with a calibration curve prepared from a reference serum with a concentration of $950 \mathrm{mg} / \mathrm{L}$. Normal values for $\mathrm{Lp}(\mathrm{a})$ were $<300 \mathrm{mg} / \mathrm{L}$.

The statistical analysis included descriptive indicators as: mean and standard deviation, minimum and maximum of

Table III. Correlations between Lp(a), lipid profile and thyroid function parameters in hypothyroid patients

\begin{tabular}{lcc}
\hline Patients & Euthyroid & Hypothyroid \\
\hline TC & +0.574 & $<0.001$ \\
TG & +0.765 & $<0.001$ \\
LDL & +0.370 & $<0.05$ \\
VLDL & +0.768 & $<0.001$ \\
TC/HDL & +0.542 & $<0.001$ \\
LDL/HDL & +0.380 & $<0.001$ \\
Apo B & +0.673 & $<0.001$ \\
Apo A/B & -0.537 & 0.001 \\
TSH & +0.542 & $<0.001$ \\
FT4 & -0.587 & $<0.001$ \\
T3 & -0.572 & $<0.001$ \\
\hline
\end{tabular}

Table II. Post-hoc Tukey test for study groups - multiple comparissons between all pairs of two groups

\begin{tabular}{lccccc}
\hline Variable & (I) group & (J) group & $\begin{array}{c}\text { Difference } \\
(I-J)\end{array}$ & $\begin{array}{c}\text { Standard } \\
\text { Error }\end{array}$ & $P$ \\
\hline Lp(a) & Hypothyroidism Hyperthyroidism & 230.15 & 43.09 & $<0.001$ \\
& & Euthyroidism & 178.28 & 37.22 & $<0.001$ \\
& Hyperthyroidism Hypothyroidism & -230.15 & 43.09 & $<0.001$ \\
& & Euthyroidism & -51.86 & 40.04 & 0.401 \\
\hline
\end{tabular}

investigated lipid parameters. Kruskal-Wallis $\mathrm{H}$ test was applied to prove that there are statistical differences between the three groups. Post-hoc Tukey test was applied to specify between which groups there are significant differences. Spearman's correlation coefficient $r$ was calculated. A value of $\mathrm{p}<0.05$ was considered statistically significant.

\section{Results}

The characteristics, clinical variables and mean levels of $\mathrm{Lp}(\mathrm{a})$ in the study groups are presented in Table I.

Serum levels of $\mathrm{Lp}(\mathrm{a})$ in hypothyroid patients (483.28 $\pm 281.55 \mathrm{mg} / \mathrm{L}$ ) were significantly higher than the values of patients from the control group $(305 \pm 100.44 \mathrm{mg} / \mathrm{L})$, and also higher than the levels found in the hyperthyroid patients $(253.13 \pm 94.29 \mathrm{mg} / \mathrm{L}), \mathrm{p}<0.05$ (Table II).

In patients with hypothyroidism we found a strong significant positive correlation between $\mathrm{Lp}(\mathrm{a})$ levels with TSH, Apo B, TC/HDL, TC, TG, VLDL levels, and a significantly mild correlation both with the LDL/HDL ratio and with LDL levels. Lp(a) levels were significantly negatively correlated with Apo AI/B, FT4 and T3 (p<0.05), as presented in Table III.

No correlation was found between TPOAb and Lp(a) levels.

In hyperthyroid female subjects we found a significant positive correlation between $\mathrm{Lp}(\mathrm{a})$ and the LDL/HDL ratio $(r=+0.398, p=0.049)$. In hyperthyroid male subjects, there was a highly significant negative correlation between $\mathrm{Lp}(\mathrm{a})$ and TG $(\mathrm{r}=-0.900, \mathrm{p}=-0.037)$, and $\mathrm{Lp}(\mathrm{a})$ and VLDL levels $(\mathrm{r}=-0.900, \mathrm{p}=-0.037)$. In patients with hyperthyroidism, no correlation was found between $\mathrm{Lp}(\mathrm{a})$ levels and the other analyzed parameters.

\section{Discussions}

The plasma concentration of $\mathrm{Lp}(\mathrm{a})$ is genetically determined (depending on the sequences of the apo(a) gene in chromosome 6q26-27) and relatively stable over time, not influenced by age, sex, diet, or most pharmacological interventions that modify other plasma lipids, except for fish oil, nicotinic acid, colestipol, neomycin and atorvasta-

Table IV. L L (a) levels and cardiovascular risk $[13,19]$

\begin{tabular}{lcccc}
\hline $\mathrm{Lp}(\mathrm{a})$ & Desirable & Borderline risk & High risk & Very high risk \\
\hline $\mathrm{mg} / \mathrm{dL}$ & $<14$ & $14-30$ & $31-50$ & $>50$ \\
$\mathrm{nmol} / \mathrm{L}$ & $<35$ & $35-75$ & $75-125$ & $>125$ \\
\hline
\end{tabular}


tin [12-15]. Drugs that inhibit the hepatic production of apo $\mathrm{B}$, intense physical activity and moderate alcohol consumption tend to lower serum Lp(a) levels [13]. The mean plasma concentration of $\mathrm{Lp}(\mathrm{a})$ is $30 \mathrm{mg} / \mathrm{dL}$. Average levels $\mathrm{Lp}(\mathrm{a})$ and the distribution curve of these levels are very different according to the considered ethnic group. One recent study showed that in different ethic groups, different genetic alterations were associated with increased $\mathrm{Lp}(\mathrm{a})$ levels $[13,15]$. The metabolic determinants of increased serum levels of $L p(a)$ are unknown. Diabetes and kidney disease are associated with increased levels of $L p(a)$ [16].

Various authors have admitted that high serum $\operatorname{Lp}(\mathrm{a})$ level is a risk factor for coronary heart disease (CHD), cere-brovascular disease (CVD), atherosclerosis, thrombosis, and stroke $[4,5,17,18]$. $\mathrm{Lp}(\mathrm{a})$ levels that increase the cardiovascular risk are presented in Table IV $[13,19]$.

The association of $\mathrm{Lp}(\mathrm{a})$ with the incidence of cardiovascular events was studied in patients with familial hypercholesterolemia. In these subjects there was a net increase both in the frequency and the precocity of coronary accidents, $\mathrm{Lp}(\mathrm{a})$ levels being found twice as high in individuals who had hypercholesterolemia and associated CHD $[2,7]$.

Data from the literature are contradictory regarding levels of $\mathrm{Lp}(\mathrm{a})$ in patients with thyroid dysfunction and on different series results with discrepancies were reported. In thyroid disorders, data obtained by us are partly in agreement with data obtained by De Bruin et al. (1993), who found in a cross-sectional study high levels of $\mathrm{Lp}(\mathrm{a})$ in patients with overt hypothyroidism $(255 \mathrm{mg} / \mathrm{L})$ and lower levels in hyperthyroid patients $(75 \mathrm{mg} / \mathrm{L})$, compared to euthyroid patients $(150 \mathrm{mg} / \mathrm{L})$ and a reference population group from a local blood collection center $(155 \mathrm{mg} / \mathrm{L})$ [20]. In another study, hyperthyroid patients (with severe thyrotoxicosis, especially with high levels of antithyroid antibodies) had elevated levels of $\mathrm{Lp}(\mathrm{a})$ compared to euthyroid subjects. Hypothyroid subjects showed elevated serum levels Lp(a) [22]. Regarding thyroid autoimmunity, it has been reported that euthyroid males and postmenopausal females with evidence of thyroid autoimmunity (increased titers of TPO-Ab and/or thyroglobulin autoantibodies) had increased Lp(a) levels $[21,23]$. Another study compared the levels of $\mathrm{Lp}(\mathrm{a})$ of 22 euthyroid subjects (9 male and 13 postmenopausal female subjects) with thyroid autoimmunity, with those of 64 age- and sex-matched controls without thyroid autoimmunity [24]. There were no significant differences in the values of lipid parameters, including $\mathrm{Lp}(\mathrm{a})$, between the two groups, even when apo(a) phenotypes were taken into account $[24,25,26]$. In subclinical hypothyroidism patients $(\mathrm{n}=38)$ a significant negative correlation was observed between FT3 levels and Lp(a) $[26,27]$.

Lee et al. compared patients covering the whole spectrum of thyroid function and found no differences of $\mathrm{Lp}(\mathrm{a})$ levels between groups. No correlation was found between Lp(a) and TSH or FT4 levels [28]. Multiple regression studies showed that $65.5 \%$ of the variability in levels of
$\mathrm{Lp}(\mathrm{a})$ were influenced by the changes in phenotype $\mathrm{Lp}(\mathrm{a})$ $(60.5 \%)$, TSH $(3.5 \%)$ and age $(0.8 \%)$. A subgroup analysis of patients with major isoforms of $\mathrm{Lp}(\mathrm{a})$ showed that $28 \%$ of the variability in concentrations of $\mathrm{Lp}(\mathrm{a})$ might be explained by changes in thyroid function (19.1\%), age $(6.5 \%)$ and TG (3.5\%). Higher correlations were found with TSH, TC, LDL and apo B levels [11,29-32].

\section{Conclusions}

The association of hypothyroidism with increased levels of $\operatorname{Lp}(\mathrm{a})$ seems to increase the already high cardiovascular risk in hypothyroid subjects, while increased levels of $L p(a)$ represents independently a relevant cardiovascular risk factor. This fact can be another argument in favour of the active evaluation of dyslipidemic patients for thyroid dysfunctions, and for unhesitating treatment of hypothyroidism. Thyroid hormones are significant modulators of $\mathrm{Lp}(\mathrm{a})$ levels, and there are multiple mechanisms responsible for changing $\mathrm{Lp}(\mathrm{a})$ levels.

\section{References}

1. Berg K. A new serum type system in man: the Lipoprotein(a) system. Acta Pathol Microbiol Scand. 1963;59:369-382.

2. Watts GF, Keamey EM, Taub NA, Slavin BM. Lipoprotein(a) as an independent risk factor for myocardial infarction in patients with common hypercholesterolaemia. Jf Clin Patho. 1993;46:267-270.

3. Zhu $X$, Cheng SY. New insights into regulation of lipid metabolism by thyroid hormone. Current Opinion in Endocrinology, Diabetes and Obesity. 2010;17(5):408-413.

4. Fruchart JC, Nierman MC, Stroes ES, Kastelein JJ, Duriez P. New risk factors for atherosclerosis and patient risk assessment. Circulation. 2004;109III:15-19.

5. Discepolo W, Wun T, Berglund L. Lipoprotein(a) and thrombocytes: potential mechanisms underlying cardiovascular risk. Pathophysiol Haemost Thromb. 2006;35:314-21.

6. Koschinsky ML. Novel insights into Lp(a) physiology and pathogenicity: more questions than answers? Cardiovasc Hematol Disord Drug Targets. 2006;6:267-78.

7. Anuurad E, Boffa MB, Koschinsky ML, Berglund L. Lipoprotein(a): a unique risk factor for cardiovascular disease. Clin Lab Med. 2006;26:751-72.

8. Zorio E, Falco C, Arnau MA, et al. Lipoprotein(a) in young individuals as a marker of the presence of ischemic heart disease and the severity of coronary lesions. Haematologica. 2006;91:562-5.

9. Santi A, Duarte M, Moresco RN, et al. Association between thyroid hormones, lipids and oxidative stress biomarkers in overt hypothyroidism. Clinical Chemistry and Laboratory Medicine. 2010;48(11):1635-1639.

10. Roos A, Bakker SJ, Links TP, Gans RO, Wolffenbuttel BH. Thyroid function is associated with components of the metabolic syndrome in euthyroid subjects. J Clin Endocrinol Metab. 2007;92:491-6.

11. Peppa M, Betsi G, Dimitriadis G. Lipid Abnormalities and Cardiometabolic Risk in Patients with Overt and Subclinical Thyroid Disease. J Lipids. 2011; 2011: 575840. Published online 2011 July 18. doi: 10.1155/2011/575840.

12. Asvold BO, Vatten LJ, Nilsen TI, Bjoro T. The association between TSH within the reference range and serum lipid concentrations in a populationbased study. The HUNT Study. Eur J Endocrinol. 2007;156:181-6.

13. Enkhmaa B, Anuurad E, Zhang W, Tran T, Berglund L. Lipoprotein(a): genotype-phenotype relationship and impact on atherogenic risk. Metab Syndr Relat Disord. 2011;9(6):411-8.

14. Bruckert E, Thomas D. Les hypercholesterolemies. John Libbey Eurotext, London, 1997, 28-53.

15. Takagi $H$. Atorvastatin decreases lipoprotein(a): a meta-analysis of randomized trials. Int J Cardiol. 2012;154(2):183-6.

16. Dumitrescu L, Glenn K, Brown-Gentry Ket al. Variation in LPA is associated with Lp(a) levels in three populations from the Third National Health and Nutrition Examination Survey. 2011 PLoS ONE 6 (1): e16604.

17. Nordestgaard BG, Chapman MJ, Ray K, Borén J, Andreotti F, Watts GF et al. Lipoprotein(a) as a cardiovascular risk factor: current status. Eur. Heart J. 2010;31(23):2844-53. 
18. Dubé JB, Boffa MB, Hegele RA, Koschinsky ML. Lipoprotein(a): more interesting than ever after 50 years. Curr Opin Lipidol. 2012;23(2):133-40.

19. George RM, Torelli J. Beyond cholesterol: 7 life-saving heart disease tests that your doctor may not give you. New York: St. Martin's Griffin. 2005 p.91.

20. De Bruin TW, van Barlingen $\mathrm{H}$, van Linde-Sibenius TM, et al. Lipoprotein(a) and Apolipoprotein B plasma concentrations in hypothyroid, euthyroid and hyperthyroid subjects. J Clin Endocrinol Metab. 1993;76:121-126.

21. Rizos CV, Elisaf MS, Liberopoulos EN. Effects of Thyroid Dysfunction on Lipid Profile. Open Cardiovasc Med J. 2011;5:76-84.

22. Boda J, Paragh G, Szabo J, et al. Lipoprotein(a) studies in thyroid diseases. Orv Hetil. 1997;138:2307.

23. Lotz H, Salabe GB. Lipoprotein(a) increase associated with thyroid autoimmunity. Eur J Endocrinol. 1997;136(1):87-91.

24. Bairaktari ET, Tselepis AD, Millionis HJ, Elisaf MS. Lipoprotein(a) levels, apoLipoprotein(a) phenotypes and thyroid autoimmunity. Eur J Endocrinol. 1999;140:474-6.

25. Tagami T, Tamanaha T, Shimazu S, et al. Lipid profiles in the untreated patients with Hashimoto thyroiditis and the effects of thyroxine treatment on subclinical hypothyroidism with Hashimoto thyroiditis. Endocrine Journal. 2010;57(3):253-258.
26. Toruner F, Altinova AE, Karakoc A, et al. Risk factors for cardiovascular disease in patients with subclinical hypothyroidism. Adv Ther. 2008; 25:430-7.

27. Dullaart RPF, van Doormaal JJ, Hoogenberg K, Sluiter WJ. Triiodothyronine rapidly lowers plasma Lipoprotein(a) in hypothyroid subjects. Netherlands Journal of Medicine. 1995;46(4):179-184.

28. Lee WY, Suh JY, Rhee EJ, et al. Plasma CRP, apolipoprotein A-1, apolipoprotein B and $\mathrm{Lp}(\mathrm{a})$ levels according to thyroid function status. Arch Med Res. 2004;35:540-5.

29. Lippi G, Targher G, Montagnana M, Salvagno GL, Guidi GC. Relationship between Lipoprotein(a) and thyroid function status in the general population. Arch Med Res. 2007;38:905-6.

30. Riche DM, East HE, Priest HM. Practical management of dyslipidemia with elevated Lipoprotein(a). J Am Pharm Assoc. 2008;48(6):803-7.

31. Neves C, Alves M, Medina JL, Delgado JL. Review Thyroid diseases, dyslipidemia and cardiovascular pathology. Rev Port Cardiol. 2008; 27(10):1211-36.

32. Teixeira P, Reuters VS, Ferreira MM, et al. Lipid profile in different degrees of hypothyroidism and effects of levothyroxine replacement in mild thyroid failure. Translational Research. 2008;151(4):224-231. 